\title{
Building inclusive cities: reflections from a knowledge exchange on the inclusion of newcomers by UK local authorities
}

Jacqueline Broadhead(i)

Correspondence: Jacqueline. Broadhead@compas.ox.ac.uk Centre on Migration, Policy and Society COMPAS, University of Oxford, Oxford, UK

\begin{abstract}
Inclusive Cities, a university led knowledge exchange initiative works in collaboration with six UK city administrations facilitating the development of their strategic and practical approach to the inclusion of newcomers in the city. The paper places this case study into the context of the UK's centralized asylum reception and resettlement policy framework, contrasting it with the increasing recognition of the importance of the local level in integration and inclusion policy and the intersections between these differing modes of governance and competencies.

The paper explores emerging learning from the programme in relation to the leadership role of local government, its ability to act as a place shaper in relation to inclusion and integration and it role in convening partners through horizontal, placebased, networks as well as the ways in which this case study can contribute to wider learning on the role of knowledge exchange in facilitating social change and policy framing at the city level and learning on the multi-level governance of reception and integration. The paper explores how mutual knowledge exchange may create space for a broadening out of the policy framing in relation to reception - in particular how a 'newcomer' frame may support increased innovation at the local level.
\end{abstract}

Keywords: Integration, Inclusion, Local government, Multi-level governance, Asylum seekers, Refugees, Reception, Innovation

\section{Introduction}

The role of UK local government in the reception and inclusion of newcomers has often been one of low salience and limited capacity, whereby a highly centralized system combines with a lack of clarity as to the role of local government in the inclusion of newcomers, to produce relative inertia. The significant retrenchment of local authority resources post 2010 and lack of statutory requirements on local government in this area may have led to the conclusion that UK government was an inactive and uninterested actor. However, in keeping with the local turn observed in other European cities (Caponio \& Borkert, 2010), integration has risen in policy salience since 2015 (Katwala, Rutter, Mohammad, \& Ballinger, 2017) both in terms of reception (defined here both specifically in relation to asylum seeker and refugee reception and in a broader sense of receptivity to newcomers in their first phase of arrival) and

(c) The Author(s). 2020 Open Access This article is distributed under the terms of the Creative Commons Attribution 4.0 International License (http://creativecommons.org/licenses/by/4.0/), which permits unrestricted use, distribution, and reproduction in any medium, provided you give appropriate credit to the original author(s) and the source, provide a link to the Creative Commons license, and indicate if changes were made. 
integration/inclusion (conceptualized here as the wider process of mutual accommodation over the longer term between all newcomer and longer standing communities.)

This paper uses learning gleaned from a sustained programme of knowledge exchange working with 6 UK cities as a case study to examine how a selection of UK local authorities are defining their policy priorities, including in the context of a highly centralized system for asylum seeker reception in particular and migration governance in general, acknowledging and reflecting upon the role of the so-called 'hostile environment,' 'Windrush scandal' and the aftermath of the EU referendum, as major factors in setting the context on inclusion for UK cities and their leadership. Using Scholten's (2016) typology on multi-level governance, it examines the intersection between the highly centralized nature of asylum reception and the increasingly localist/ multi-level nature of policy making on integration to understand the ways in which policy makers frame policy problems and how they choose to (de) prioritise questions of integration and reception. The findings have both scholarly and applied contributions in the following areas;

a. scholarly contribution to the understanding of multi-level governance of integration in UK cities and the finding of simultaneous increase of integration salience coupled with the lack of a natural home for integration policy and practice within local government. When combined with the inverse (centralized) situation for asylum reception, the paper develops applied findings on the policy consequences of this as they pertain to local leadership and convening powers as methods for place shaping.

b. contribution to the ways in which emergent frames - in particular related to 'newcomers,' may challenge existing dominant ways of thinking within local authority policy making, which currently focus on migration status categories or statutory equalities categories and how this policy framing process may support local policy makers and partners to carve out additional space to develop their approach and interventions.

\section{UK policy context on reception and inclusion}

\section{Asylum reception in the UK}

The UK policy and management approach to asylum reception and inclusion is principally characterised by its highly centralised nature, in large part divorced from local governance. Using Scholten's typology of the multi-level governance of migration and integration (2016) the vertical and centralised approach to migration is contrasted by, what is at least nominally, a more localist approach to integration utilising the principle of subsidiarity (as in the general power of competence for local government set out in the Localism Act 2011.) However, Darling (2016) demonstrates how the approach to asylum reception and dispersal acts in decidedly decoupled way. For Scholten, decoupling occurs where 'policy interests are not always aligned ... conflicts do take place.' In contrast to the multi-level governance model highlighted in the typology where there is some 'levelling' of the hierarchies between different tiers of government, the UK asylum system demonstrates both a highly vertical hierarchy and one which emanates from central government - operating almost wholly independently from the scope of local government. 
Post 2000, the structure of asylum reception in the UK has been characterised by a centralised system in which the Home Office sub-contracts the provision of accommodation in dispersal areas to a number of private contractors and directly provides subsistence support to claimants through the National Asylum Support Service. Local government and civil society stakeholder participants in the National Conversation on Immigration (2018) identified a number of challenges in the governance of this scheme specifically in reference to its links (or otherwise) with local government, in particular highlighting the lack of communication between commissioned private providers and councils, the low standard of accommodation and lack of equitable distribution of asylum seekers around the country as major issues and areas in which they wished to see change in the current system (and over which they presently lack direct control and have limited influence and voice.) The issue of unequal geographic distribution of asylum seekers has been the subject of commentary related to the award of new private contracts in late 2018 and led to several local authorities threatening to withdraw their consent for the programme to operate in their area- an example of the decoupling of interests and subsequent potential for conflict as identified by Scholten. In part, this is due to the privatisation of provision by central government and subsequent ongoing issues with the quality of these contracted services (as identified by Darling (2016)). However, it also has a wider cost in the perceived lack of coherence in local policy making on these issues. Not only are the policy aims and objectives of local and central government decoupled but local government is effectively shut out of decision making and partnerships, with local councils describing themselves as 'increasingly side lined' ("Asylum seeker system in Yorkshire," 2018) from the process. Tension also exists within the system at the point of transition between the centralised system for asylum seekers and the more localised mainstream welfare assistance for newly recognised refugees with the All Party Parliamentary Group on Refugees (2017) identifying that, 'the move on period [between grant of status and exiting NASS provision] currently results in newly recognised refugees facing homelessness and destitution.'

In contrast to the asylum dispersal system, there are a number of areas in relation to the reception of newcomers over which local authorities do have direct control and which continue to act as a focal point for targeted interventions by local authorities. These include opt-in resettlement schemes including the Syrian Vulnerable Person's Resettlement Scheme (VPRS), Child at Risk Scheme and Gateway programme as well as the National Transfer Scheme for Unaccompanied Asylum Seeking Children including through the Dubs Amendment.

The contrast between asylum dispersal and the approach taken for resettlement is particularly striking; in the Syrian VPRS scheme the Home Office and the Ministry for Housing, Communities and Local Government (MHCLG) work directly with participating local authorities, providing funding and programme requirements identified by the All Party Parliamentary Group on Refugees (2017) as somewhat akin to an integration framework (even if not identified thus) and moving towards (if still, ultimately, hierarchical in favour of central government,) Scholten's definition of multi-level governance as the interaction and joint coordination of relations between the various levels of government without clear dominance of one level' and the Syrian VPRS demonstrates how, when it is in the interests of central government, agency can be given to local government over areas of reception, from which they are otherwise excluded. However, 
the APPG highlights how the disparity in governance between the two routes creates a two tier system of provision between resettled refugees and those whose status is decided in country, identifying how 'refugees who are resettled in the UK receive dedicated support ... there is often a lack of such support for refugees who have been recognised through the UK's asylum process.' This can be observed both in the differential outcomes for individuals, but also in the disparity of governance arrangements over the two schemes and the lack of institutional and policy coherence between and within them.

\section{Integration and inclusion policy at the local level}

Where the direct experience of asylum reception has been largely either centralized or decoupled, there is greater evidence of a localized approach when it comes to integration and inclusion. The city has, in recent years, become a focal point for policy, practice and research relation to the inclusion of newcomers from abroad (Caponio \& Borkert, 2010.) This focus can be both understood demographically, in that cities have an overall higher rate of migration in proportion to their size as well as tending to experience change that is rapid (Penninx, 2003) and being the areas most likely to become super-diverse (Vertovec, 2007). Hatziprokopiou, Frangopoulos, and Montagna (2016) identify two roles that migration plays in defining the city stating that on the one hand their role in 'the historical growth and expansion of cities ... in processes of capitalist development, [which] has conditioned the production and direction of migratory flows. On the other, migration and the migrants themselves (re) shape the city and urban life, and contribute to wider processes of urban change.'

Migrants, therefore, have a significant role in defining the city from both a social and economic lens. Equally, as newcomers impact significantly on the core responsibilities of city administrations - from planning, to jobs and housing, to education and community safety, they are likely to be salient to the formulation of policy and practice at the municipal level.

In the UK, recent policy developments including the publication of the Integrated Communities Strategy Green Paper (2018) and action plan (2019) for England have attempted to frame the local level as central, with the Green Paper setting out to implement a national framework of priorities locally, stating that the Paper 'signals a new local approach to integration.' However, in spite of this, few local authorities have a specific integration strategy and there is no UK wide strategy. Post 2010, there appears to have been limited capacity devoted to the integration and inclusion of newcomers at the municipal level with the All Party Parliamentary Group on Social Integration (2017) identifying a 'tangled division of responsibility for integration policy between central government departments and agencies [which] has been compounded by the lack of an agreed view as to the role of local government in this policy area.'

Similarly, whilst the Organisation for Security and Co-operation in Europe's (OSCE) defines integration as a: 'dynamic, multi-actor process of mutual engagement that facilitates effective participation by all members of a diverse society in the economic, political, social and cultural life, and fosters a shared and inclusive sense of belonging at national and local levels,' it has not always been interpreted in this manner. Whilst the Integrated Communities Green Paper, highlights that 'integration is not assimilation ... 
integration is a two way street' previous reviews have shown a focus upon Grillo's (2007) unintended policy outcome of 'enclavement.' Two significant policy reviews (Cantle (2001) and Casey (2016)) focussed on this aspect, encapsulated in the phrase 'parallel lives' underlining the challenges of isolated communities, segregation and differentiated outcomes and life chances based on background. Although much critiqued, both methodologically (Crossley in relation to the Casey review, 2018) and substantively, this policy framing remains a pertinent part of the ongoing UK policy discourse.

Integration sits within this policy ecosystem, which includes many wider drivers, including but not exclusively, the impact of the EU referendum, migration governance and policy - in particular the impact of the hostile or compliant environment (a suite of policies enacted by the UK Home Office with the intention of excluding irregular migrants from accessing public services) and its role in the subsequent Windrush scandal (these restrictions being wrongfully enacted upon British citizens and/or longstanding residents who did not have documentary evidence to prove their citizenship and/or leave to remain.) As with asylum, the centralised nature of these schemes, mean that they exist predominantly outside of the remit of local government, but their impacts are felt locally - both through restricting access to services, but also as Hatziprokopiou et al. identify in inhibiting the role of migrants in shaping and defining the city and its identity. Similarly, whilst there is a limited role for local government in the Brexit process, a number of drivers are pertinent, from the local impacts (both technical in relation to advice needs for EU nationals, but also wider community concerns) to the sense, perceived or otherwise, of a cleavage between Remain voting cities and their surrounding Leave voting smaller towns and rural areas (Toly, 2017.)

All of which has provided both challenges and opportunities for local government in general and cities in particular in engaging in the integration agenda - even where theoretically this is an area in which they have competence and are well placed to act in the localised way identified in Scholten's typology (though the more proactive roles played by the devolved administrations in Wales and Scotland do appear to show a more multi-level exemplar.) On the one hand, a recognition of the potential negative effects of a failure to do integration well (particularly in cities with high levels of recent migration which characterise all of the participating Inclusive Cities), has been contrasted with the significant retrenchment of local authority resources post 2010, which has challenged local government to take on any role beyond its statutory duties and has left integration trapped as something which local authorities understand as important in the medium to long term (and feel the effects of a lack of in the present) but struggle to identify the capacity and impetus to take action.

\section{Methodology}

\section{Inclusive cities: a knowledge exchange initiative}

The Inclusive Cities programme is a knowledge exchange initiative in which learning arises from the knowledge exchange itself, rather than from a discrete research project. Though distinctive from other forms of university involvement in city innovation such as learning labs (Keith \& Headlam, 2017) it aims to facilitate new ways of approaching issues, and acts as a horizontal approach to joining up partnerships between university research and policy. 
Spencer (2017) conceptualises knowledge exchange as 'a long term, iterative, process through multiple interactions over time; as when researchers are embedded in institutions to facilitate that process or as a single or series of engagements for a more intense process of exchange.' This kind of knowledge exchange moves away from the dissemination of research findings into a two-way process in which both the practitioners and the researcher are co-producing knowledge though 'social partnership and joint governance' (Nerlich, 2015) in order to contribute to the decentering of academic knowledge and hierarchies.

Boswell and Smith (2017) highlight four distinct models for the intersection between research and policy - (1) knowledge shapes policy; (2) politics shapes knowledge; (3) co-production; and (4) autonomous spheres. Where the first two are distinctly linear, with the second often seen to be compromising to academic independence, in the co-productive model, the 'production' of knowledge itself, means that, 'they [social enquiries] do not simply describe the world as it is, but also enact it.' (Law and Urry, 2004) or as Jasanoff (2004) describes it, they are 'mutually constitutive.' As Weiss (1979) underlines, this is particularly apt in areas in which, 'the use of research is only one part of a complicated process that also uses experience, political insight, pressure, social technologies, and judgment.' In these circumstances, the process of 'impact' is not linear, but instead 'one of continuous mutual influence and reinforcement' (Boswell \& Smith, 2017) and capturing and understanding this impact becomes more complex. This is particularly pertinent to Inclusive Cities which aims to facilitate social change, as well as studying it.

In this way, the project mirrors some 'insider research' models (Coghlan \& Brannick, 2007) (though it is distinctive as the researcher in this case is not a complete organisational member) and has some similarities with 'researcher in residence' models (Marshall et al., 2014), most prominently seen in the healthcare field which, acknowledging the gap between theory and practice, propose the researcher in residence as a bridging model - similar to the knowledge brokerage role identified by Ward (2017).

Whilst Coghlan and Brannick argue that this insider research is considered separately to the 'broader debate on knowledge creation and transfer between practitioners and academics,' there is considerable overlap between the privileged (yet complex) role of the researcher embedded within an organisation and the design of a knowledge exchange initiative. Coghlan and Brannick identify four particular dynamics of 'insider research;' access, 'preunderstanding,' role duality and managing organisational politics. Whilst each of these dynamics are relevant to Inclusive Cities, the duality of the 'organisational and researcher role' is the most pertinent for a project which is both a knowledge exchange and from which emerging learning has been identified. Coghlan (2019) further identifies that action research within one's own organization (or project in this case) takes place within the present tense' and so the researcher must show how a process of iterative reflection and the creation of long term and quality collaborations and partnerships have developed in order to allow for 'rigour, reflectivity and relevance' whilst acknowledging that action research (or its equivalent) cannot seek to be judged 'by the criteria of positivist or interpretative science, but must seek its own criteria.' 
Implications for the design and methods of the inclusive cities programme

These considerations are embedded within the design of the Inclusive Cities programme whose knowledge exchange methodology encompasses three main types of exchange, facilitated peer learning between the cities, policy maker/ researcher exchange between the dedicated researcher and the participants through action planning and synthesis of research findings for a policy audience (Morton, 2016) and international learning exchange. In keeping with its iterative mode of knowledge exchange, Inclusive Cities builds upon previous 'city working group' models bringing together groups of European cities alongside academic input.

The recruitment of the cities was based on a long list of UK cities with high levels of recent migration and sought to recruit a demographic, geographic and politically diverse group of cities. The project works with 5 cities, Bristol, Cardiff, Glasgow, Liverpool and Peterborough with London joining some aspects of the project as an Associate Member. The programme is local authority led with each city nominating a strategic and operational lead (the implications of this are discussed below.) In keeping with the aim to both study and facilitate social change, the project requires each city to develop an action plan defining priority areas on inclusion and then implement this through a taskforce of stakeholders made up of partner organisations throughout the city.

Learning from the project is derived from a number of sources, including data from an anonymous survey of participating officers and politicians. However, predominantly, learning comes from the long term iterative process of facilitating and understanding and analysing policy development by the researcher within the participant local authorities, observation of taskforce and internal meetings, individual discussions and meetings with officers and politicians and the facilitated convenings which the project has hosted to bring the participating cities together. These methods require the researcher to play a dual role, as outlined above, and to operate in the 'present tense', untangling and understanding organisational aims and objectives in real time. It necessarily means that the learning generated is predominantly from a local authority perspective - and is concerned with policy making frames and choices (rather than service delivery impacts - though these frames can and do lead to significant impacts both in terms of resource allocation and policy change.) However, as with Coghlan's conception of action research, this process is supplemented with the critical distance to reflect on policy maker actions as well as the impact of the wider ecosystem on the drivers, motivations and contexts which influence these decisions.

\section{Conceptualising integration, reception and newcomers - existing and emerging policy framing}

Whilst often used semi-interchangeably by policy makers, integration, inclusion, reception (and other terms, not considered here, but widely used by policy makers such as welcoming and social cohesion) come from markedly different research traditions and have different meanings.

Reception is used here in two distinctive ways, firstly in reference specifically to the initial accommodation of asylum seekers through the centralised dispersal system outlined above. However, there is a wider conceptual sense of reception which refers to the receptivity with which a community welcomes newcomers. McDaniel, Xiomara 
Rodriguez, and Wang (2019) conceptualise this as a temperature scale of the 'warmth' with which a community is receptive and define receptivity as it has been used across a wide range of research disciplines as 'a broad set of attitudes, concepts, feelings, ideals, and cultural, economic, political, social, and spatial structures that shape how a particular place receives migrants and newcomers' as well as how migrants themselves perceive their reception. Reception is conceptualised here as attitudinal, referring here to 'being open to new suggestions; open to arguments, ideas, or change; and tending to receive new ideas favorably.' Reception therefore is both a technical term relating specific policy challenges (in this case relating to asylum and refugee reception) and a wider attitudinal sense of receptivity. However, what these two distinctive interpretations share is a temporal frame - the sense that they are both focussed on work with newcomers in the initial stage of their arrival.

By contrast integration, though also lacking a clearly defined shared definition relates not only to this initial period but a longer term process of mutual accommodation which can describe both policy processes and their outcomes. Inclusive Cities draws specifically on Spencer and Charsley's (2016) model of integration which sets out the following features integration, namely that it:

i. is concerned with both newcomers and receiving communities, that this is a mutual, two-way process and this should be reflected in policy making

ii. takes place across society (not only through public services) and so requires a range of actors to be involved and to take shared responsibility

iii. is not a single process but takes place across a number of domains: structural (as in the labour market); social, cultural, civic participation, and in relation to identity and mutual belonging. The interplay between these is complex, can go forwards or backwards over time and an experience in one may impact on the experience in another

iv. can be impacted by a wide range of external factors across these domains. This includes policy interventions and well as human capital, social networks and opportunity structures (such as access to the labour market or housing)

v. takes place, mostly, at the local level

As part of the knowledge exchange principles which inform the project, these factors have been built into the design of the project with the identification of the newcomer frame as central, the focus on the local level, the development of a taskforce model to promote shared responsibility in partnership and the action planning model taking place across a number of policy domains in order to translate policy framing into service delivery realities.

Though this 'newcomer' frame is a central feature of the Inclusive Cities model and Spencer and Charsley's conception of integration, it has not been the predominant policy frame in UK local government discourse in which two other frames have dominated the discourse.

As Bacchi (2000) identifies, policy frames are not neutral - they shape the ways in which policy discourses are framed and presented, noting, 'the point here is to recognize the non-innocence of how 'problems' get framed within policy proposals, how the frames will affect what can be thought about and how this affects possibilities for action.' 
The two prevalent examples in UK local government discourse on integration are migration status as a frame (drawing on categories of migration status used at the national level to group communities according to immigration status at the local) and equalities as a frame (focussing on the differentiated opportunities and outcomes for different groups - in parallel to those set out in the Equality Act 2010.)

These two tendencies have strong imprints on local authority practice and the way that they shape the policy 'problems' which are being responded to. In the case of migration status, the use of differentiation by migration category encourages policy makers to focus predominantly on particular migrant groups (often those that they have direct statutory responsibility for - as seen in the delineation identified by the APPG in their 'two tier system.') This framing also replicates the centralised issue of migration governance into the local context - subtly reinforcing the primacy of migration over integration (and perhaps hinting as to the reasons why the former is centralised, while the latter is devolved.)

In the equalities frame, the dominant equalities agendas of the 1990s to mid 2000s (Worley, 2005) tends to group second and third generation long standing BAME communities with 'newcomers' - as they are both (seen to be) included within the protected characteristic of race. These policy frames remain, even where their structural manifestations (such as specific Equalities teams and departments) may no longer exist and can therefore drive policy prioritisation and decision making.

By contrast, Alexander (2003) attempts to use 'host/stranger' relations, in order to identify policy maker attitudes towards migrants, and how these shape the response of the policy maker; transient, guest worker, assimilationist, pluralist and interculturalist. Instead of viewing integration solely through the dominant frames outlined above, this typology provides a newcomer/ longer standing resident frame which trades a focus on specific, delineated categories of migrant (asylum seeker, refugee, economic migrant) for a temporal frame. Newcomer is here defined broadly as 'the newly arrived' in contrast to the longer standing residents. Some scholars, particularly within the education context have attempted to provide a more precise definition of newcomer (for example Rodriguez (2018) defines newcomers as those arriving in the last year.) However, more important than this precise definition is the move to a temporal frame. This has two implications, firstly - it delineates between migration and ethnicity - including BAME residents within the category of 'longer standing communities.' Secondly, 'newcomer' widens the consideration of which types of migrants count for local policy making whether these policies focus solely on those within the direct remit of local authorities (such as refugees and asylum seekers) or if they include broader groups and the policy implications of this.

\section{Emerging learning from inclusive cities}

The emerging findings of the Inclusive Cities programme seek to open out these factors and understand if they have created conditions for change in the context of providing innovation in the reception of newcomers within the city in the following areas:

- The developing role of local leadership at the city level to facilitate the inclusion of newcomers 
- The role of place shaping in creating new narratives for change

- The role of partnerships in the development of horizontal networks

\section{Developing local leadership}

Inclusion and integration have risen in UK policy salience in the participating cities, from an admittedly low base - with several cities reporting that the aftermath of the EU referendum had increased interest and widened the scope of policy ambition. However, in spite of this, there remains a lack of a well-defined 'home' for integration in UK local government.

The project has been placed in different departments in each city; ranging from a dedicated social integration team, through to neighbourhood directorates, those working directly with refugees and asylum seekers, community cohesion and community safety teams and economic regeneration directorates and has been led by both senior officers and politicians. This is partly a logical result of the differing priorities in each area in order to place the project in the correct area of the local authority, but also reflects a policy rootlessness within UK local government. This is in contrast to the United States, for example, where de Graauw (2015) identifies city offices as key capacity building organisations (whilst acknowledging that their capacity is often also limited.) According to de Graauw these offices perform two key functions - providing leadership and the power to convene - roles also identified as crucial by all of the participating cities and integral to the structure of the project. As advocated by Katwala, Somerville, and Ballinger (2016), in 2016 London appointed a dedicated Deputy Mayor for social integration making it the first UK city to somewhat replicate this model and, in recognition of the capacity challenges, other cities have started to explore strategic secondments into political offices (for example, two policy advisors have been seconded into Mayor's City Office in Bristol to lead on this issue.)

This leads to two key insights in relation to local leadership on inclusion. Firstly, that there remains no natural home for integration in UK local government and, as a result, it is difficult to generate the policy space to engage on this issue in a substantive way (in particular in England, excluding the increased capacity in London) as a result of this lack of not only resource, but strategic capacity. Whilst advocated in the 2016 Mayoral elections, specific Deputy Mayors or Offices for integration or migrant affairs have not emerged in UK cities (with some notable exceptions.) However, there is an appetite to provide greater leadership on integration, as evidenced through the appointment of dedicated leads and the development of strategic action plans in each city. In appointing these leads, each city has attempted to take a wider view of integration beyond simply replicating targeted asylum seeker and community cohesion priorities, through to a broader conception of integration placed in the context of place shaping.

\section{Developing a broader, place shaping framing of integration at the local level}

As outlined above, as well as facilitating peer learning, the project has also worked with cities to implement research findings on integration - using Spencer and Charsley's (2016) framing of newcomers and longer standing communities as a way of supporting cities to reframe their integration practice. The project defines newcomers broadly as 'all those who have recently arrived in the city' (Broadhead, 2017) and, as outlined 
within the theoretical framework above is interested both in newcomers and 'host,' 'receiving' or 'longer standing' communities.

Primarily the broad 'newcomer' frame includes those groups often excluded from policy discussions on integration because they are perceived as being 'betwixt and between' (Grillo, 2007) either because they are seen as 'transient' within Alexander's typology or as high skilled 'citizens of the world' who do not require policy intervention. By including these groups, such as high skilled workers and international students, there is evidence (from the action plans) that cities have been able to widen the scope of their integration focus, with the opportunity to build on the asset based community development models of, for example, Kretzmann and McKnight (1993) and Mathie and Cunningham (2003) rather than only focussing on the barriers to inclusion and deficits, perceived or otherwise, of certain groups. This offers the opportunity of mainstreaming inclusion and integration into wider policy agendas - with a particular focus on the emerging UK policy agenda surrounding inclusive growth. The Local Government Association (2017) identifies local authorities as having 'a unique understanding of their local economies, with ownership over the key levers of local growth,' placing central importance on the skills initiatives which can provide coherence within the 'whole skills system' in order that they make sense for both local communities and employers. However, migration has been almost entirely absent from the occasionally fuzzy conversations in relation to defining and understanding an inclusive growth policy agenda (Lee, 2019) underlining how migration and integration remain somewhat side lined within UK local government policy considerations and the ways in which a 'newcomer' outlook could shape broader city-wide policy responses.

As an example of this shift, Glasgow has outlined an explicit attraction strategy through the development of an International Strategy - aiming to increase its population whilst ensuring that this demographic growth brings benefits across the community. This has meant the need for specific initiatives to encourage the retention of international students post-graduation and support the translation of qualifications gained overseas, at the same time attempting to communicate the benefits (economic and otherwise) to longer standing residents. This has taken the city's integration policy beyond the narrower focus on targeted communities such as asylum seekers and Roma populations, (though, it is important to note, that the city has not erased its targeted initiatives which still run in parallel.) Whilst, it must be acknowledged that this sits within the context of Scottish Government strategy including the New Scots strategy, which shares a newcomer focus alongside a targeted focus on refugees, this marks a potentially significant shift in policy framing, though the full substantive impact on service delivery remains to be seen.

Similarly, London's social integration strategy captures its intended commitment to shared responsibility for the whole community for integration in its title; 'All of Us' which has a core focus on promoting three dimensions; relationships (promoting shared experiences), participation (supporting Londoners to be active citizens) and equality (tackling barriers and inequalities.) This focus on social contact, participation and equality sets a broad agenda for inclusion, encompassing both newcomers (though not explicitly with a 'newcomers' frame in this case) and longer standing communities.

This framing applies both to the internal strategic priorities and external communications such as in taking the lead in developing place-based narratives of inclusion, which 
aim to tell the story of the city as a place of inclusion. This broader picture of local leadership posits the local authority as 'place shaper' (Lyons, 2007) and aims to foster innovation in reception through the development of wider strategic communications in order to build new narrative of inclusions.

In keeping with McDaniel et al.'s (2019) findings on receptivity as attitudinal, this place shaping framing focusses on how reception activity is not only linked to service delivery but also on 'creat [ing] the fertile soil for people to put down roots and work together as neighbors, and allow [ing] welcoming places to successfully navigate challenging times that have the potential to derail community cohesion like leadership transitions or economic events' (Welcoming America, 2017).

Examples of this wider conception of reception, through place shaping include the 'We are Bristol' and 'Our Liverpool' campaigns which aim to help newcomers to settle into the city and 'get to know their neighbours' based on the idea that 'welcoming is something that comes naturally to Liverpudlians' or are seeking to build inclusion into existing externally focussed city branding campaigns such as 'London is Open,' and 'People make Glasgow.' The aim of this wider approach is to create the conditions of welcoming - supplementing targeted initiatives with an ethos of shared responsibility across the authority (and the city) with the aim of placing reception for newcomers within a strategic culture of inclusion. This echoes Lyons (2007) wider role for local government in setting the identity and ethos of a place stating that 'they must be part of a broader debate about the type of country we want to live in: the balance we strike between citizen, community and government in terms of both power and voice, and how we manage the inevitable tensions between diversity, choice and a desire for common standards.'

However, this wider conception of a place based narrative of inclusion which sees reception and integration as broader cultures of 'receptivity' needs to be balanced with the overall continued low salience of integration and relative lack of both service capacity, in which it has often been grass roots community groups who have taken a lead on integration at the neighbourhood level, covering for the perceived gap in local authority activity. Similarly, in focussing on these broader and less tangible areas of provision, there is a risk that local authorities lose sight of or are able to skirt around more concrete areas of service delivery - in particular in relation to mainstream services such as the provision of housing, social care and planning frameworks. In order to be effective these policy frames need to continue to be tethered to change in service delivery, which while not the focus of this paper, will be crucial to the success, or otherwise, of the approach.

\section{Convening of horizontal networks by city authorities to promote inclusion}

If an increase in local leadership and in developing broader place based narratives of inclusion, would seem to hint at a more proactive role for local government in this arena, then it should be noted that as scholars such as Darling (2010) have highlighted, local cultures of welcome such as they exist have largely been driven by NGOs and faith groups. If local government is to play a more significant role in integration, then its

${ }^{1}$ A standalone workshop hosted at the Migration Museum in March 2018 supported the development of coproduced draft guidelines on the development of a 'shared narrative of inclusion.' 
convening power (as identified by De Graauw) will be central in bringing together horizontal networks.

\begin{tabular}{|c|c|c|c|c|c|}
\hline \multicolumn{6}{|l|}{ Overview of Taskforce membership } \\
\hline Type & City 1 & City 2 & City 3 & City 4 & City 5 \\
\hline Schools & $x$ & & $x$ & $x$ & \\
\hline Further Education & & $x$ & $x$ & $x$ & $x$ \\
\hline Higher Education & & $x$ & $x$ & & $x$ \\
\hline Voluntary Sector Forum & $x$ & & $x$ & $x$ & $x$ \\
\hline Transport Provider & & $x$ & & & \\
\hline Grassroots community group & $x$ & $x$ & & $x$ & \\
\hline National charity (local chapter or central) & & $x$ & $x$ & $x$ & $x$ \\
\hline Large employer & & $x$ & & & $x$ \\
\hline Small/ medium sized employer & $x$ & & $x$ & & \\
\hline Other Public Sector & & & $x$ & $x$ & \\
\hline Housing association & $x$ & $x$ & $x$ & & \\
\hline Employer representative organisation & & $x$ & $x$ & $x$ & \\
\hline Arts, culture and heritage & $x$ & $x$ & $x$ & $x$ & \\
\hline Trade union & $x$ & & & & \\
\hline \multicolumn{6}{|l|}{ Local media } \\
\hline Charitable foundation & $x$ & & & & $x$ \\
\hline Central UK government or devolved administration representative & & & $x$ & $x$ & $x$ \\
\hline
\end{tabular}

The Inclusive Cities model formalises a Taskforce of stakeholders as the model for institutionalising this, with the aim to play a dual role - to both act as a stakeholder board to provide feedback on the action plan, but also to take the initiative outside of the specific competences and policy influence of local government and for the different stakeholders to act as champions for inclusion in their respective sectors.

These taskforces have significant areas of continuity (such as the presence of the NGO representatives and of education providers in every city), each city having tailored their grouping both to reflect their priorities and local context. However, whilst this variation shows the importance of local context, it also in some ways illustrates the limitations of the model, whereby the Taskforce reflects the existing relationships and partnerships rather than the capacity to reach out to new partners.

This is linked to the dual function of the Taskforce - both in gaining buy in and legitimacy for the programme, whilst also taking the initiative to lead out into their respective sectors. Survey feedback from participants highlighted that the Taskforces have functioned much more in the former function than the latter. In this way the 'levelling' described by Scholten as a function of multi-level governance may be seen as absent here, where the leadership of the local authority is accompanied by a recreation of local hierarchies - supporting partners to be involved and consulted, but often inhibiting them from taking a more co-productive role. At the same time, the previous absence of local government from integration sphere had not seemingly produced a great deal of strategic activity (notwithstanding often very strong targeted cultures of welcoming, particularly in relation to refugee and asylum issues), suggesting that the convening and leading role is an important one for local government and that there is not 
another natural partner who can take this lead in its absence. However significant challenges remain in its ability to deliver - in particular in relation to building relationships outside of public sector and migrant specific NGO partners.

The taskforce model somewhat mirrors the 'Local Strategic Partnership' (LSP) model established by New Labour and more or less abolished in 2010. Geddes, Davies, and Fuller (2007) in examining the theory of change of LSPs identify that both a vicious and virtuous cycle can exist within these arrangements, but identify a series of relevant assumptions about their modes of operation - namely that they are conditioned by the national policy context but their response is driven by local factors and that their effectiveness depends upon 'networked governance' including the strength of preexisting relationships and 'the extent to which it is able to influence the actions of partners, both among other public sector partners, but also from the business, voluntary and community sectors' and the way in which this governance 'adds value to the activities of the partners.'

Within this model (occasionally cited by participating cities as a pre-cursor to the, albeit more targeted, Taskforces) we can identify the leadership and convening role identified by de Graauw evolving into a 'networked governance' role of shared and potentially co-produced social change. However, the limitations of this model can also be seen in this horizontal governance model - whereby partnership may be limited and superficial' - either seeing the local authority as overly dominant or conversely, where a lack of local authority capacity inhibits the ability to drive forward change against agreed shared objectives.

Within Inclusive Cities, the positive theory of change can be seen in the composition of taskforces with a move towards more networked governance and the development of a shared vision and narrative throughout the city in relation to inclusion. For example, Bristol's creation of a City Office and City Plan - which covers integration as part of a wider remit and which is facilitated by the local authority but defined as a shared city wide campaign. However, whilst acknowledging the variance between cities, there are some significant shared limitations. The most notable amongst these is the difficulty, in keeping with the ambition of the broader, 'newcomer' frame, to reach out beyond existing partners and communities. All cities have found it difficult to gain sustained employer engagement and few have chosen to include community groups representing longer standing communities (alongside migrant groups.) Similarly, whilst a number of cities originally proposed including local media as part of their taskforce (in particular identified as a driver for developing local narratives of inclusion) none has succeeded in making this a long-term part of the partnership, with the importance of independence cited by some outlets as a rationale for not participating. These limitations may reflect the capacity (and/or expertise) on behalf of the local authority and others in reaching out, or they may be more reflective of a lack of interest in the agenda in the targeted sectors, however, they are indicative of the complex factors at play in making horizontal, place based networks functional and supportive in a way which can surpass the limitations of previous partnership arrangements in UK local government and instead contribute to true networked governance which embeds the concept of a 'shared responsibility' for inclusion. Similarly, whilst the Lyons supposition, supported by de Graauw and the local turn identified in migration studies, that local government is best placed to convene and act as a place shaper is upheld by the design of Inclusive Cities, 
it is also necessary to underline its limitations and challenges in being truly coproductive particularly in relation to its capacity and expertise in forging long term and sustainable partnerships.

\section{Conclusion}

The contrast between the decoupled and fractured relationship between local and central government in the management of asylum reception and the more localized nature of integration in UK policy discourse provides the context for a knowledge exchange initiative which seeks to reframe the policy problem of building more inclusive communities at the municipal level. In decentering research expertise and using the co-productive methodology of knowledge exchange it seeks to increase the policy space in which UK cities can develop their approach and allow for innovation and provide a case study for the use of knowledge exchange in this area.

In keeping with the growing literature emphasizing the importance of the city and local level within integration policy practice there is a growing recognition of integration and inclusion as areas of policy salience within the participating UK local authorities. However, beyond this, the programme highlights the opportunities which arise from the wider 'newcomer' and place shaping framing of integration and inclusion, using empirical research findings to facilitate local authority responses aiming to move beyond the current piecemeal, narrowly targeted initiatives to a broader framing of inclusion - encompassing both reception and integration as 'everyone' issues of shared responsibility which engage both newcomers and longer standing communities. Emerging learning from the initiative demonstrates the potential for sustained local leadership and use of convening powers to bring the, at present, relatively peripheral and underfunded areas of reception and integration closer to the centre of discourses on place shaping, local leadership and, eventually, through into mainstreamed service delivery. Initial learning from the programme has found a number of local authorities taking a step change in this direction to provide strategic leadership through greater prioritization of integration and a wider conception of reception - with a particular interest in developing place based narratives of inclusion as a core function of local leadership.

However, whilst the programme finds an increasing salience and prioritization for participating policy makers, the lack of dedicated resource or structural capacity to deliver act as severe constraining factors to delivery. Existing policy frames focused on targeting groups by immigration status (reinforcing centralized migration governance framing) as well as the role of an equalities framing (sidelining the impact of newcomer communities and narrowing the policy focus) shape local government responses on these issues demonstrating the continued structural challenges of breaking out of the imprints of siloed practice which predominantly promote targeted interventions focused on particular migrant groups, serving to inhibit the mainstreaming of inclusion as a shared responsibility and the use of asset based models which make the local case for inclusion.

Finally, this paper has not been able to consider two interlinked and important areas which will ultimately determine the success or otherwise of these policy frames. Firstly, looking downwards towards the link between policy framing and 
its application locally into service delivery in order to affect real change for residents and secondly, looking upwards, in the capacity of cities to advocate effectively for shifts in the centralized migration governance and reception practice. It will ultimately be these two areas of leadership - both local and national - which will allow these inclusive frames to become both resourced and embedded at the local level.

\section{Abbreviations}

APPG: All Party Parliamentary Group; MHCLG: Ministry for Housing, Community and Local Government; Syrian VPRS: Syrian Vulnerable Person's Resettlement Scheme

\section{Acknowledgements}

Not Applicable.

\section{Authors' contributions}

The author read and approved the final manuscript.

\section{Funding}

The Inclusive Cities programme is funded by the Paul Hamlyn Foundation. PHF was not involved in the design of the study or in the collection, analysis, and interpretation of data or in the writing of the manuscript.

\section{Availability of data and materials}

Not Applicable.

\section{Competing interests}

The author declares that she has no competing interests.

Received: 14 May 2019 Accepted: 22 January 2020

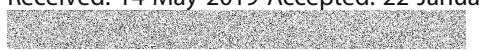

\section{References}

Alexander, M. (2003). Local policies toward migrants as an expression of host-stranger relations: A proposed typology. Journal of Ethnic and Migration Studies, 29(3), 411-430.

All Party Parliamentary Group on Refugees (2017). Refugees welcome? thE experience of new refugees in the UK https:// reliefweb.int/sites/reliefweb.int/files/resources/APPG_on_Refugees_-_Refugees_Welcome_report.pdf.

All Party Parliamentary Group on Social Integration (2017). Integration not demonisation http:/thechallenge.org/uploads/ documents/APPG-Integration-not-Demonisation-Report.pdf.

Asylum seeker system in Yorkshire at risk of "catastrophic failure", region's leaders warn Sajid Javid (2018, August 18). Yorkshire Post. Retrieved from https://www.yorkshirepost.co.uk/news/latest-news/exclusive-asylum-seeker-system-inyorkshire-at-risk-of-catastrophic-failure-region-s-leaders-warn-sajid-javid-1-9307805.

Bacchi, C. (2000). Policy as discourse: What does it mean? Where does it get us? Discourse: Studies in the Cultural Politics of Education, 21(1), 45-57.

Boswell, C., \& Smith, K. (2017). Rethinking policy 'impact': Four models of research-policy relations. Palgrave Communications, 44, 3.

Broadhead, J. (2017). Inclusive cities background paper inclusive practices for newcomers at city level and examples of innovation from overseas. Oxford: COMPAS http://unw.compas.ox.ac.uk/media/Inclusive-Cities-Background-Paper-Oct-2017-FINAL.pdf.

Cantle, T. (2001). Community cohesion: A report of the independent review team. London: Home Office.

Caponio, T., \& Borkert, M. (2010). The local dimension of migration policy making' IMISCOE reports. Amsterdam: Amsterdam Univ. Press.

Casey, L. (2016). The Casey review: A review into opportunity and integration. London: Department for Communities and Local Government.

Coghlan, D. (2019). Doing action research in your own organisation. London: SAGE.

Coghlan, D., \& Brannick, T. (2007). In defense of being "native": The case for insider academic research. Organizational Research Methods, 10(1), 59-74.

Crossley, S. (2018). 'Telling it like it is'? A critical perspective on the casey review into opportunity and integration https:// discoversociety.org/2018/05/01/telling-it-like-it-is-a-critical-perspective-on-the-casey-review-into-opportunity-andintegration/ Accessed 11 Dec 2019

Darling, J. (2010). A city of sanctuary: The relational re-imagining of Sheffield's asylum politics. Transactions of the Institute of British Geographers NS, 35, 125-140.

Darling, J. (2016). Asylum in austere times: Instability, privatization and experimentation within the UK asylum dispersal system. Journal of Refugee Studies, 29(4), 483-505.

de Graauw, E. (2015). Rolling out the welcome mat: State and City immigrant affairs offices in the United States IdeAs ideas.revues.org/1293.

Geddes, M., Davies, J., \& Fuller, C. (2007). Evaluating local strategic partnerships: Theory and practice of change. Local Government Studies, 33(1), 97-116.

Grillo, R. (2007). Betwixt and between: Trajectories and projects of transmigration. Journal of Ethnic and Migration Studies, 33(2), 199-217.

Hatziprokopiou, P., Frangopoulos, Y., \& Montagna, N. (2016). Migration and the city. City, 20(1), 52-60.

Jasanoff, S. (Ed.). (2004). States of knowledge: the co-production of science and the social order. London: Routledge.

Katwala, S., Rutter, J., Mohammad, A., \& Ballinger, S. (2017). Integration: From national rhetoric to local reality. How the new mayors for city-regions can help get integration right at local level. British Future www.britishfuture.org/wp-content/ uploads/2017/04/Mayors-and-integration-report.FINAL_pdf. 
Katwala, S., Somerville, W., \& Ballinger, S. (2016). Making citizenship matter. Why London needs an Office for Citizenship and Integration. British Future www.britishfuture.org/wp-content/uploads/2016/02/Citizenship-report-Final.26.02.16.pdf.

Keith, M., \& Headlam, N. (2017). Comparative international urban and living labs the urban living global challenge: A prospectus https://www.urbantransformations.ox.ac.uk/wp-content/uploads/Comparative-International-and-Urban-Living-Labs-\%E2\% 80\%93-The-Urban-Living-Global-Challenge-A-Prospectus.pdf.

Kretzmann, J., \& McKnight, J. (1993). Building communities from the inside out. Chicago: ACTA Publications.

Law, J., \& Urry, J. (2004). Enacting the social. Economy and Society, 33(3), 390-410.

Lee, N. (2019). Inclusive growth in cities: A sympathetic critique. Regional Studies, 53(3), 424-434.

Local Government Association (2017). Industrial strategy briefing https://www.local.gov.uk/sites/default/files/documents/ LGA\%20Industrial\%20Strategy\%20Briefing\%20-\%201\%20December\%202017.pdf.

Lyons, M. (2007). The Lyons inquiry into local government https://www.webarchive.org.uk/wayback/archive/20070428120000/ http://www.lyonsinquiry.org.uk/docs/final-complete.pdf.

Marshall, M., Pagel, C., French, C., Utley, M., Allwood, D., Fulop, N., ... Goldmann, A. (2014). Moving improvement research closer to practice: The researcher-in-residence model. BMJ Quality and Safety, 23, 801-805.

Mathie, A., \& Cunningham, G. (2003). From clients to citizens: Asset based community development as a strategy for community-driven development. Development in Practice, 13(5), 474-486.

McDaniel, P., Xiomara Rodriguez, D., \& Wang, Q. (2019). Immigrant integration and receptivity policy formation in welcoming cities. Journal of Urban Affairs, 41(8), 1142-1166.

Morton, S. (2016). Evidence synthesis for knowledge exchange: Balancing responsiveness and quality in providing evidence for policy and practice. Evidence \& Policy, 14(1), 155-167.

Nerlich, B. (2015). The coproduction confusion. Blog University of Nottingham Making Science Public http://blogs.nottingham. ac.uk/makingsciencepublic/2015/03/20/the-co-production-confusion/.

Penninx, R. (2003). Integration: The role of communities, institutions, and the state. Migration Policy Institute http://www. migrationpolicy.org/article/integration-role-communities-institutions-and-state.

Rodriguez, S. (2018). "Risky" subjects: Theorizing migration as risk and implications for newcomers in schools and societies. European Education, 50(1), 6-26.

Scholten, P. (2016). Between National Models and multi-level decoupling: The pursuit of multi-level governance in Dutch and UK policies towards migrant incorporation. Journal of International Migration and Integration, 17(4), 973-994.

Spencer, S. (2017). The global exchange approach to knowledge exchange. Oxford: COMPAS http://www.compas.ox.ac.uk/ media/GEM-approach-to-knowledge-exchange-paper-030417-1.pdf Accessed 9th January 2019.

Spencer, S., \& Charsley, K. (2016). Conceptualising integration: A framework for empirical research, taking marriage migration as a case study. Comparative Migration Studies, 4, 18.

Toly, N. (2017). Brexit, global cities, and the future of world order. Globalizations, 14(1), 142-149.

Vertovec, S. (2007). Super-diversity and its implications. Ethnic and Racial Studies, 30(6), 1024-1105.

Ward, V. (2017). Why, whose, what and how? A framework for knowledge mobilisers. Evidence \& Policy, 13(3), 477-497.

Weiss, C. (1979). The many meanings of research utilization. Public Administration Review, 39(5), 426-431.

Welcoming America (2017). Welcoming standard and certified welcoming https://www.welcomingamerica.org/sites/default/ files/Welcoming\%20Standard\%20\%2B\%20Certified\%20Welcoming.pdf.

Worley, C. (2005). 'It's not about race. It's about the community': New labour and 'community cohesion'. Critical Social Policy, 25(4), $483-496$.

\section{Publisher's Note}

Springer Nature remains neutral with regard to jurisdictional claims in published maps and institutional affiliations.

\section{Submit your manuscript to a SpringerOpen ${ }^{\circ}$ journal and benefit from:}

- Convenient online submission

- Rigorous peer review

- Open access: articles freely available online

High visibility within the field

- Retaining the copyright to your article

Submit your next manuscript at $\boldsymbol{\nabla}$ springeropen.com 